\title{
The conversation that never stopped
}

\author{
Anna Sfard ${ }^{1} \mathbb{B}$ \\ Accepted: 27 July 2021 / Published online: 6 August 2021 \\ (c) FIZ Karlsruhe 2021
}

I am unlikely to be called David's "old friend". I do consider myself his friend, but our friendship began just a few years before his premature death. True, I have been familiar with David Clarke's name for almost as long as I have been doing research in mathematics education. Which member of this community wouldn't? For years, echoes of his ingenious activities reverberated throughout the community. He was looming large as the initiator, organizer, and leader of the ambitious, world spanning undertaking called the Learner's Perspective Study. In this project, he hoped to complement TIMSS $^{1}$ cross-cultural video research on teaching with a comparable one on student learning. Even without meeting him, I admired him for the boldness and breadth of his researcher's vision. His writings spoke for themselves.

During all this time, there was also a sort of personal acquaintance. Even from afar I could tell that David loved traveling and never missed an occasion to meet new people. This "flying Australian", as I came to call him in my thoughts, was never deterred by the distance, sometimes quite considerable, he had to traverse to attend a conference or to see a colleague. Drop a pin on the map, and the odds were that you hit a place that David visited at least once. It was thus not surprising that we would see each other every now and then, here and there, at one international convention or another. For many years, however, there was nothing more in those momentary path-crossings than "Hi, how are you?", "Good to see you again!" and, on rare occasions, "We need to talk one day". In the end, I could recognize David at a distance and even without approaching him was able to figure out what he would say to me if I did. I thus felt I knew him. Yet, once our mingling rituals reincarnated into a proper conversation, I realized that nothing of what I knew about David so far prepared me for the person I eventually found.

\footnotetext{
1 Trends in International Mathematics and Science Study.

Anna Sfard

sfard@ netvision.net.il

1 Faculty of Education, University of Haifa, 31905 Haifa, Israel
}

It was David who turned the promise of our talking to each other "one day" into the urgent "let's talk now!" In the midst of his preparations for 2010 AERA, he emailed me with a proposal. "As usual", he wrote, "I am using AERA to explore issues that are of interest to me". His "current concern" was "the need for the education community to address the challenge of research synthesis." Such synthesis would have to address the issues of both method and theory and would probably end up being domain-specific. "Would you be interested in taking on the discussant's role for this symposium?" he asked. At that time, David was already well known for his networking acumen-for his ability to connect people from all over the world. Now it was my turn to become one of these lucky "connected" individuals. I was happy to accept his invitation even though, at that time, I was unaware of the fact that I was opening the Sesame gate. All I expected was a one-time, potentially inspiring professional exchange. What I found was a lasting conversation that never ceased to excite. And also a new friendship.

Indeed, almost instantly, the episodes of collaboration occasioned by David's conference symposia became our annual tradition. From the first instance, I could see a number of reasons to continue. To begin with, these events were invigorating. By organizing them, David was creating a steady supply of opportunities for people like me to try new ideas and to revamp old ones. Moreover, the professional deal he was offering to his collaborators included social delights. This meant, above all, having a dinner in carefully chosen company in an expertly selected restaurant, always one of the best in town. David himself was fun to be with. Whether social or strictly professional, the occasions he organized had three common components: laughter, laughter, and laughter.

Before long, both of us felt the need for a more substantial conversation than our brief and crowded conference meetings could offer. In Spring 2016, over a lunch in Berkeley, where I stayed for a sabbatical and David visited on his way to AERA, it was suggested that I come to Melbourne. I was to spend my time there talking with David and his vibrant research group, while also helping myself to the enormous 
database initiated in the Learner's Perspective Study, and then being constantly fed with the stuff coming from David's newer research projects. The goodies multiplied much faster than even the hungriest of researchers could devour, and David, always forthcoming and generous, was happy to share these delicacies with interested colleagues. One more attraction was the legendary Science of Learning Research Classroom, or SLRC for short, that David created in his Research Centre in the University of Melbourne. I definitely wanted to see this wonder of the world of mathematics education. Tempted and freshly retired, I was easy to convince. And so, in May 2017, I embarked on the flight that took me from Tel Aviv to Singapore and from there, to Melbourne.

I relocated to David's kingdom, the International Centre for Classroom Research (ICCR) in the University of Melbourne, for the period of 6 weeks. From the very first moment the place dazzled me with its vibrant activity, almost all of it generated and constantly fueled by David. My high expectation notwithstanding, what was done in the Centre managed to surprise me. I was amazed by the number, quality and organizational ingenuity of the multifarious activities that took place there. So first, there were three large-scale cross-national research projects running in parallel. The International Classroom Lexicon Project was bringing together researchers from Australia, Chile, China, Czech Republic, Finland, France, Germany, Japan and the USA. Each of the national groups was charged with analyzing the professional vocabulary (or "pedagogical naming system") of mathematics educators from its country. Together, the groups were supposed "to reconceptualize classroom practice and advance educational theory". In the project known as Learning from Lessons, David and his team studied "the structure and construction of mathematics teacher knowledge in Australia, China and Germany". The third project, The Social Essentials of Learning, was, according to its subtitle, "an experimental investigation of collaborative problem solving and knowledge construction in mathematics classrooms in Australia and China". Initially, this was supposed to be a rather modest-sized study, conducted locally, with children and teachers from one sizeable school in Melbourne. Yet, as if by itself, it had quickly spun into the international network of studies, now known by the acronym INSEL (International Network of the Social Essentials of Learning). It seems that small-scale low-profile studies were just not David's style.

As if these three world-embracing endeavors were not enough, David served also as a co-investigator in the futuristic enterprise called The Innovative Learning Environments and Teacher Change (ILETC) project. I was fortunate to have an opportunity to attend one of his long meetings with the partners. The bold ideas about what the school of the future may look like made me wish to return to the classroom as a student. Now, one pandemic and hundreds of zoom meetings later, the memory of the images I saw and explanations I heard in this meeting constantly reminds me that in spite of the current talk on learning out-of-school or at distance, dedicated school space will probably never lose its allure.

Small chunks of the future envisioned by ILETC people seemed to be already happening in David's hi-tech SLRC, the big classroom endowed with moving tables of adjustable sizes and designed with utmost care for both usefulness and aesthetics. Students could be seated here any way they or their teacher wanted, individually or in groups, in rows or in circles, in stable or constantly changing arrangements. And since the space was also meant as a site of research, it was equipped with at least ten cameras. Next to this dream classroom, there was the backroom full of multiple screens, with the help of which one could unobtrusively monitor the classroom activity and control the process of recording. This adjacent room was also the place for visitors wishing to observe the classroom without being seen themselves. The data SLRC had been generating were unprecedented in their resolution and detail. I thought about this unusual place as a high-tech incubator of research ideas.

It was interesting to observe David 'in the wild', in his natural habitat. As long as I was looking at his impressive undertakings from afar, I imagined him to be always too busy to have time for anything but work. With so much responsibility, I thought, he should not be expected to find more than a few minutes, here and there, for a visitor like myself. Nor should I hold it against him if, due to the overdose of professional meetings, he would not show much appetite for socializing. Indeed, the onus of running the overly busy hub of research activity would have made most people tense and nervous, and possibly not much fun to be with. Yet, as I soon learned, David was not one of these people. He ruled his territory with exceptional ease, flair and grace. The game of positioning himself as a person who wields power was not his thing. Within this context, his most endearing feature was the capacity for looking at himself with a healthy dose of irony. No wonder he seemed to be adored by all those who worked with him-bosses, peers, subordinates and students alike.

My 6 weeks in Melbourne were the perfect mixture of hard work and social pleasures. Between our lively conversations, seminars, project meetings, and visits to local schools, David and I, together with David's other collaborators, prepared three symposia for 2018 AERA to take place in New York. David was planning these events with the enthusiasm of a young person organizing a party. He loved good life, and the good life, for him, was one among people whom he found interesting and could make happy, if only for a moment.

After I left Melbourne, each one of us, David and I, separately spent a couple of months traveling. In November, 
when I finally returned home, I received a disquieting email, sent from David's address, but with a subject line mentioning him in the third person, "News: Update on David". It turned out to be written by Sharon, David's wife, who was informing me about David's illness. Sharon tried to soften the blow with the reassuring "He is his usual witty, smiling self", supported with evidence in the form of a current photo.

During the following months I was in regular contact with Sharon, from whom I learned that the situation was not improving. But I also corresponded with David, and his emails and text messages were bringing a different message. In all these encounters, David appeared in high spirits and full of his usual energy. At his request, we even had a Skype meeting devoted to our further collaboration. I found David's courage vis a vis the illness admirable and reassuring. I hoped it could save him. I felt this way also during the 2018 AERA in New York City, where the three symposia we prepared during my 2017 stay in Melbourne were taking place without him.

David's emails continued being cheerful and upbeat even when doctors started losing hope. "Life is the usual mixture of joy and challenge. But joy continues to lead! I am so lucky!", he texted me in the early fall of 2019. The report about his current work followed: "I am working on the culmination of three projects (Lexicon, Social Unit and Learning from Lessons). This is SO satisfying. As you would expect we have another grant application in (-)". And then, with his eye firmly on the future, "I am hoping that one of my project ideas will provide a pretext for collaboration and visits between us. Please stay well and be in touch". These sentiments repeated themselves in mid-November, in the email signed jointly by him and Esther: "We continue to look forward to meeting at AERA or elsewhere in 2020. In the interim, the possibility of collaboration with you is always something on our mind. We must make sure that this possibility to share new ideas is always available to us."

In mid-January 2020, amongst the Australian wildfires and the incipient COVID-19 pandemic, all this came to an abrupt end. In this apocalyptic atmosphere, David passed away peacefully, surrounded by his family.

To those around him, David was many different things, sometimes coming in rather unusual combinations. To some of his colleagues he was simultaneously the boss to defer to and a buddy to enjoy a good life with; or a mentor whose voice should always be heard and a careful listener, whose ears stayed open and whose mind and heart were open as well. There were many versions of David, but one of them could not be missed by any of his acquaintances, whether professional or private: for all those who knew him, David was a conversational partner. More than anything else, he seemed to love talking with people, whoever they were, wherever he found them. It was this passion for conversation that fueled his sustained networking effort. Thus, if I were to characterize David in just one word, conversationalist would be my choice. Always interested in people and ideas and easily excited by both, David lived for, and through conversation.

Our shared interest in communication was what brought us together. Exchange with others had been David's passion both as an activity to engage in, and as one to ponder on. For me, human communication had been the object of study, and analyzing conversations constituted both my day job and a favorite pastime.

It is thus not surprising that the visit in Melbourne remains in my memory as a 6-week long multichannel conversation. Usually, in addition to David and me, this conversation involved one or more of David's colleagues. On most occasions, we were accompanied by Esther Chan, the manager of the SEL project and David's frequent co-author. Also present in some of the meetings was the Lexicon project manager, Carmel Mesiti. Within changing settings, David and I were talking with each other practically every day. On weekdays, our meetings took place in the university cafeteria or over lengthy lunches in one of the nearby restaurants. On weekends, our conversations ran as the soundtrack for such fun-activities as a walk in a forest or in the famous Melbourne Botanical Garden; a visit to David's grandchildren, who were only too keen to show grandpa the chickens they just got from Doug, his brother; or a stroll in the city, punctuated by visits to cafes or restaurants. David's contagious good humor protected us from losing interest or getting tired. After a day filled with conversation, unable to stop, we would often email each other late in the evening with new ideas that occurred to us in the meantime.

Many of these conversations are now stored in my computer thanks to the small Olympus recorder Esther was always bringing with her to our cafeteria meetings. We were recording these exchanges hoping that one day we would collect our playfully juggled ideas, cast them into a mold and turn them into a disciplined academic text. Or two. For obvious reasons, these plans never materialized. ${ }^{2}$ But the recordings are still here, and listening to them was the first thing I instinctively started doing while preparing for this essay. This activity turned out addictive, if also somewhat frustrating. Our words, uttered against the hum of other human voices, the rattle of cutlery and the hiss of the coffee machine were sometimes difficult to hear. Our own frequent laughter made deciphering the exact words even harder.

\footnotetext{
2 This is true also with regard to papers that David would co-author. Esther and I did publish a joint paper based on data from the SEL study (Chan \& Sfard, 2020). David participated in the initial discussions regarding this paper and in an early analysis of the data.
} 
While listening to our voices, I felt as if nothing has changed. David's enthusiastic tone, his thoughtful questions and incisive responses, his jokes and laughter, were all here, as if he had never left. Even the mouse-pad I was using - the one that I borrowed from David in Melbourne and which I forgot to return - was the same as then, when David was around. It was at this point that I thought about trying to share the exhilarating experience of our ongoing conversation. By making our unorderly, hoarse dialogue public, I thought, I would be bringing David back to life also for others. It was David in action, unplugged.

Take the conversation that took place approximately a week after my arrival, ${ }^{3}$ as a representative instance. David appeared to this meeting in a black T-shirt with the drawing of a white cat proudly exposed on his chest. This attire, and especially the cat, contrasted nicely with the university setting within which our conversation was taking place. Who would have guessed, I thought, that the person with the cat was one of this university's most illustrious professors and one of the big shots of his world-wide professional community? I was wondering about the sources of the drawing and David volunteered the explanation: the cat was the work of his 6-year-old granddaughter. "You will meet the person who drew the cat", he promised. I asked him for permission to take photos, first of the cat and then of David himself with the cat. "I will be showing this picture around so people know the truth about the great David Clarke", I teased. He was happy to grant his consent: "Yes, go ahead. My granddaughter will be honored".

The topics of our meetings were carefully planned. This time, the conversation was supposed to evolve around the term commensurability. Both David and I had been pondering over this notion for quite a while. This was hardly surprising considering its importance for our understanding of the activity of communication. David was preoccupied with the issue of commensurability of differing research accounts of the same event. I was asking what happens to the learner when the discourse she has been participating in is about to change, seemingly disqualifying some of those things that, so far, she considered as true. In both cases, the term (in) commensurability could be seen as referring to a relation between stories-either researchers' stories about students' and teachers' actions, in which the storytellers tried to make sense of these actions; or learners' stories, in which students made sense of the functioning of mathematical objects. To prepare for the conversation, we exchanged papers: I was to read David and Esther's recent text on the topic ${ }^{4}$; they were to get acquainted with my thinking by reading my musings on theories, and on the challenges of incommensurability that come with multiple theorizations of the same phenomena. ${ }^{5}$

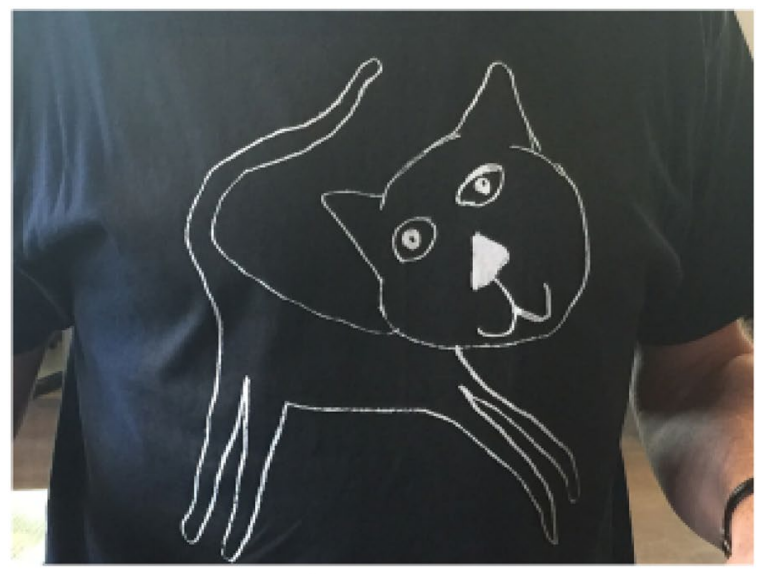

The cat

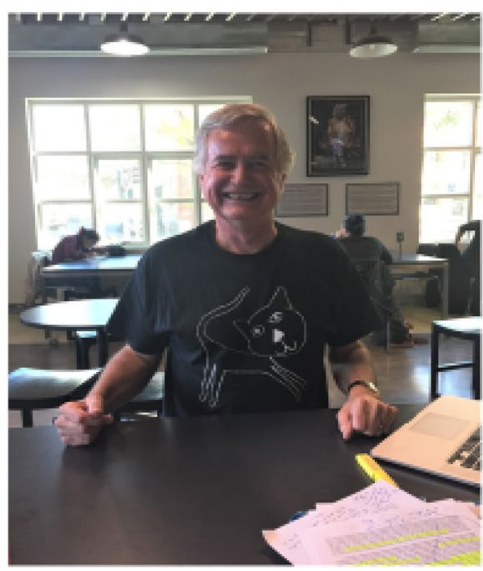

David with the cat
Esther and David's paper made me wonder about differences between their take on the topic and mine. Was it possible that my interlocutors and I we were telling incommensurable stories about incommensurability? I needed to know more about their approach. "I'm trying to understand your point of departure", I said. "What was the need from which this paper of yours was born?".

3 The text was slightly edited for comprehensibility.
Although guided by this question during the next two hours, we zigzagged, made detours, and ventured in unexpected directions. From time to time, David would throw a reminder "The question was 'Where does the interest in incommensurability came from?". Yet, forced to meander

\footnotetext{
${ }^{4}$ Chan and Clarke (2017).

5 Sfard (2018).
} 
around frequent interruption and accidental digression, we were unable to stay focused on this query for more than a few minutes. But although by the end of that day my understanding of David's take on commensurability was still somewhat shaky, I felt I did learn quite a few important things about how he thought about research in general and about his research in particular. From what he was saying, and even more so from how he was saying this, I could glean his interests, sensitivities, and his special conversational talents. Here are a number of randomly chosen insights David gave me that day, into his thinking about research he had been doing for at least a quarter of a century. I wish the written text were also able to convey the energy and excitement with which his talk was always imbued.

On juxtaposing different participants' accounts of the same classroom situation. In LPS, in this 1998 study, we elicited accounts from the teachers and from many of the students in a class. The idea was that in order to understand a video recording, you need to reconstruct it from the perspective of each of the participants. And we constantly wondered to what extent the narrative accounts generated by the participants in the different settings were commensurable with each other. Or in other words, to what extent did the students and teachers talk to each other and could be in some sense connected? And our goal was not a consensus or even a convergence. It's not a court of law where a decision must be made about what there really is. We had to juxtapose the participants' accounts. Our analyses raised the question: If indeed, there are multiple stories that can be told, how are these stories situated in relation to each other? And this is where the incommensurability comes into play. This was challenge number one.

On incommensurability of researchers' culturally distinct accounts of the same classroom situation. We wished to elicit from classroom situations what we felt was of value, that is of instructional quality. And in a study like this, it is possible that where you see structured, strategic rehearsal of essential knowledge, I see rote learning. And here comes challenge number two: Yoshi ${ }^{6}$ and I look at the same situation and we construct our own accounts. And these accounts reflect culturally-specific assumptions about not just the intentions, the purposes, but also the consequences, their values...

I would look at the Japanese lesson, Yoshi would look at the Australian lesson. In the end, each one of us

\footnotetext{
${ }^{6}$ Yoshinori Shimizu was co-PI of the LPS study, together with David Clarke and Christine Keitel. Within the project, he was the leader of the Japanese team.
}

would have looked at both the Australian and the Japanese. Our premise was that I might see something that he would not see, either because he shared the cultural assumptions of the situation with the participants or because the linguistic tools available to him precluded sensitivity [to this something].

We looked at what was being foregrounded. You made a nice point in the paper that it is not possible to act a-theoretically. That you inevitably bring to research/ observation/analysis some form of prearranged positioning and you prioritize particular themes. Sometimes you may even not recognize the underlying structure. One of the aims was to foreground my own structures. It was the interaction between myself and my colleagues from other countries that helped me to bring them to the fore. These folks would interrogate me: Why do you say this? How can you say such things about this situation? And I would ask them 'How can you not?'

Let me get back to incommensurability, which is relevant also in this contexts. This kind of analysis was, of course, subjective to the set of criteria within the framework in which the analysis was conducted. And here came the question: 'How do we juxtapose and connect researchers' accounts? If Yoshi derived a critique of Australian classroom from his vision of Japanese classroom, on what platform might his and my narrative accounts of Australian classroom be connected?'

On incommensurability of researchers' theoretically distinct accounts of the same classroom situation. So, relating culturally distinct narrative accounts from our study is one context where incommensurability may come in. This would be relatively simple if Yoshi and I by and large always shared a common theoretical perspective and just brought different cultural lenses to our case. The resulting accounts, though different, could be still commensurable. But there is the second context, in which incommensurability is a challenge: What if in fact we held quite different theoretical positions? So we set up a science study where we generated narrative accounts grounded in quite distinctive theoretical positions: positioning theory, systemic functional linguistics, variation theory, distributed cognition.... The intention was at this point to create accounts of the same situations in each one of them. These accounts may be incommensurable.

On complementarity of accounts. I posited the notion of complementary accounts. This became the signature methodological approach for the LPS: no particular account was honored as the preeminent, including the researcher's account. But we agreed that each account 
represented a distinctive perspective and if we were to understand the individuals who were participants in the particular situation, then each of their accounts had to be seen in relation to other accounts.

What I am arguing for in our incommensurability discussion is that, given disjoint theoretical vocabularies, to attempt some notion of theoretical synthesis is a nonsense. However, the accounts achieve connection, and to some extent performative coherence, through their relevance and implications for the common situation. They are performatively connected to the situation. This is really important. They are not about the same thing, and importantly not. But they are complementary. In no context so far you used the word complementary, but we used it a lot. Complementarity is very important. This is fundamental. For 25 years complementary was a key word for me.

Our conversation that day, as in any of those that followed, paused without a clear closure. My initial questions about our respective visions of incommensurability of researchers' accounts and on the issue of what to do with potentially incommensurable interpretations of classroom situations have been partially answered, but many ends were still dangling in the air. This said, I was not disappointed. My long experience as both participant and analyst of such conversations taught me that this is how these exchanges unfold, especially if people are really curious and listen to each other. The possibility of rambling, pursuing free associations and drifting away at whim is a part of their charmand a reliable source of serendipitous discoveries. Within this context, the drawing on David's T-shirt reminded me of Lewis Caroll's Cat from the Wonderland and of what he said to Alice when asked for directions.

Alice: Would you tell me, please, which way I ought to go from here?

The Cat: That depends a good deal on where you want to get to

Alice: I don't much care where-

The Cat: Then it doesn't matter which way you go...

Alice: $\quad .$. - so long as I get somewhere...

The Cat: Oh, you're sure to do that, if you only walk long enough
Fortunately, my stay in Melbourne provided me with ample time for walking and getting somewhere. We did take such walks time and again, and with sustained interest and zest. It is exactly because of this lack of closure that I feel as if our joint journey has never stopped.

Conversations, unlike their participants, live beyond their bodily manifestations. Through them, the conversationalists stay alive as well, with their identities remaining as visible as they were while still embodied in a living person. While listening now to our not-yet 4-year old conversations, I can sense David's insatiable appetite for life. Hearing his voice, and especially his laughter, I feel his contagious vitality and his almost magical ability to breathe life into his interlocutors. With his gregarious bearing and his sustained interest in others, he was bringing new meaning to the old cliché "humans are social creatures".

It is a great injustice that the life of the person who was the source of so much light and laughter to others would end so early, so prematurely. While David's professional wisdom will stay with the many who admire his work, his love for life and for people will always be with those who loved him. But most importantly, the conversations he started will go on. And so will his laughter.

\section{References}

Chan, M. C. E., \& Clarke, D. J. (2017). Learning research in a laboratory classroom: Complementarity and commensurability in juxtaposing multiple interpretive accounts. In T. Dooley \& G. Gueudet (Eds.), Proceedings of the Congress of European Research in Mathematics Education, Dublin, Ireland (pp. 2713-2720).

Chan, M. C. E., \& Sfard, A. (2020). On learning that could have happened: The same tale in two cities. Journal of Mathematical Behavior. https://doi.org/10.1016/j.jmathb.2020.100815)

Sfard, A. (2018). On the need for theory of mathematics learning and the promise of 'commognition.' In P. Ernest (Ed.), The philosophy of mathematics education today (pp. 219-228). Springer.

Publisher's Note Springer Nature remains neutral with regard to jurisdictional claims in published maps and institutional affiliations. 